The International Journal Of Engineering And Science (IJES)

|| Volume || 6 || Issue || 2 || Pages || PP 48-51 || 2017 ||

ISSN (e): $2319-1813$ ISSN (p): $2319-1805$

THE IJES

\title{
The Ecological Environmental Protection Marxism Idealogy and Its Implications for The New Rural Construction Process in Vietnam
}

\author{
Shu Yuan Zhao ${ }^{1}$, Pham Huy Thong ${ }^{2}$, Nguyen Thi Thuong ${ }^{3}$, Pham Thanh Trung ${ }^{4}$ \\ ${ }^{1}$ Prof. PhD Shu Yuan Zhao, College of Marxism studies of Hunan University, Changsha, Hunan, China (410082) \\ ${ }^{2}$ Pham Huy Thong, College of Marxism studies of Hunan University, Changsha, Hunan, China (410082); \\ Hatinh University, Hatinh, Vietnam \\ ${ }^{3}$ Nguyen Thi Thuong, Hatinh University, Hatinh, Vietnam \\ ${ }^{4}$ Pham Thanh Trung, Hoalu University, Ninhbinh, Vietnam
}

-ABSTRACT

Since the 1890s of the $19^{\text {th }}$ century, in "Dialectics of Nature" works, Friedrich Engels wrote: "we should not be too proud of our successes against the natural world. Because every time we achieve a success, the natural world will revenge us". So far Friedrich Engels's warning have still had practical value for the protection of rural environment in Vietnam.

Key words: Environment, Marxism, Protection, Rural, Vietnam

Date of Submission: 19 January 2017 Date of Accepted: 15 February 2017

\section{INTRODUCTION:}

Through Karl Marx and Friedrich Engels's warning on current status of rural environment pollution in Vietnam, it can be realized that protecting the environment has become an urgent issue which each of us must be aware of close relationship between natural environment and human beings. This is the basis for every Vietnamese citizen to conduct right actions and solutions to protect the ecological environment, towards the sustainable development of rural areas in Vietnam.

\section{KARL MARX AND FRIEDRICH ENGELS'S WARNING ON NATURAL DISASTERS}

At early formation, human totally depend on nature, depend on "the blind impact of forces not under control "[7]. Gradually, along with the impact process on nature, working tools were developed, people were aware, and understood the natural rule. Then, people dominated and changed by the natural world. Once grasping the nature rule, "human created these changes, made nature serve the purpose of dominating the natural world "[7]." People began to dominate the natural world and every time there is a step forward each time, it extended the human eye "[7]. These were the premeditated activities, plan ahead and focus on certain goals. Animals in survival process also constantly impact on the natural world, but their impact to the natural world seems to be nil and especially, they absolutely have no sense of their actions. Animals just taking advantage of the natural world to satisfy the instinct needs. In contrast, people with pre-determined objectives, using the different ways have been gradually discovering nature, control, and "only human can print up the traces of wills on earth"[7].

Thus, material producing activity is the human activity which has purpose, and was performed through human labor. Human must conduct working, impact on nature to produce material goods in order to increase economic growth; this is the objective requirements of society, is the basic and prerequisite condition which today as well as thousands of years ago people must conduct daily and hourly to maintain their life and ensure the society's development. On the other hand, the impact on nature to produce material property is not only the basis of ensuring the society survival but also as a basis for creating other social relationships, create links between human and human, and human and. However, this impact will not be excessive to lead to the break system of human-nature-society, a large and overarching system in living systems, because they are all consistent elements dialectically and most closely, regulate and complement each other in the survival and development process.

By impacting on the natural and modifying the natural, human gradually dominated nature. It is the human's victory, but we are gradually forgetting what Friedrich Engels had reminded for a long time that: "In 
nature, there is nothing happened alone, this phenomenon impacts on another phenomenon and vice versa "[7]. If human impacts on nature, change nature in order to serve their own purposes, the nature also has adverse impact on human by corresponding consequences. Human increasingly strong impact on the nature, the society can achieve more in science and technology. But if this influence is not based on an understanding of the natural rules, society rules, the results that we achieve only "the original". When mentioning about this issue, Friedrich Engels also criticized the naturalistic perspective of history that "only the natural affects to humans, only natural conditions in everywhere regulate the development of human history. This view is one-sided; it forgets that humans react again to the natural world, natural modification "[7]. Nature always moves and develops in accordance with objective rules-the available natural rules. Society is a part of nature - special part separated from the natural world. Humans exist in society, is the product of the evolution of the natural world, always follow the laws of nature and society. Since humans and human society have appeared, the nature has been developed more plentifully. The impact of nature on society is spontaneous, and the impact of society on nature is intended, so the impact of humans on nature will take place in two different directions: impacting properly as the rule make the natural developed, develop society, and improve human life. In contrast, if people impact on nature and not follow the rule, this will make nature poorly, and the relationship among nature- human- society will be broken. Historically, we have had civilizations developed brilliantly as the Mayan civilization that Friedrich Engels cited, but unfortunately until today it only recorded mark on the historical pages. The reason is because people and their hand of man has affected excessively to nature. Therfore, has reminded us that "we absolutely cannot dominate the natural world as an aggressor to dominate another nation, like a person living outside the natural world ... All our nature domination are because of us, we are different from all the other creatures since we are aware of the nature laws of nature and can use those laws correctly "[7]. On the other hand, in order to resolve the conflict between human and nature, human is only based on the awareness, but also have a change in actions, particularly the change in the manufacturing process.

\section{CURRENT STATUS OF THE RURAL ECOLOGICAL ENVIRONMENTAL PROTECTION IN VIETNAM}

In Vietnam, after 30 years of innovation, the rural ecological environmental protection has made positive changes. However, for the pressure of the process of industrialization and modernization associated with developing new rural areas, ecological environmental pollution is at an alarming rate. According to statistics of the Ministry of Natural Resources and Environment, each year in rural areas, tens of millions of tonnes of domestic waste arise, of which about $80 \%$ waste, waste water and pesticides packages- hazardous waste are not collected and treated in an appropriate manner, but discharged directly into the environment ... making rural water sources and atmosphere severely contaminated. The overuse of chemical fertilizers, growth stimulants, plant protection agents, pesticides in non-compliance with technical processes, not ensuring insulating period; massive aquaculture, lack of planning, non-compliance with the technical processes ... are major sources of toxic waste which are harmful to the environment. Accordingly, many diseases have spread rapidly, causing huge economic losses and serious threat to people's health.

In addition, the environment in the rural vocational villages of our country is now facing serious pollution. With nearly 4,600 vocational villages and craft activities in rural areas, in addition to the positive impacts, they create more jobs for millions of workers, the pollution level and the percentage of people infected there tend to increase strongly, life of people also has fallen and has been lower 10 years than the national average life of people. Many vocational villages have not handled the problems relating to waste and wastewater, causing loss of landscape and polluting the rural ecological environment. Todays, waste management in the rural areas is ignored. Evenly, in many areas, ponds, lakes and deep areas are used to discharge waste, forming open disposal sites which do not ensure technical processes and pollute surface water and underground water sources. Besides, indiscriminate exploitation of natural resource, without planning, evenly to the point of extinction has negative impacts on the environment and is the cause of the abnormal changes of the climate, causing great damage to agricultural production, properties and lives of people.

The cause of this situation is because the rural ecological environmental protection awareness of communities living and producing in rural areas is not high; awareness of environmental pollution risks in rural areas and the negative impacts of environmental pollution on the socioeconomic life and health of people of various levels of government authorities, organizations and individuals in charge in many rural areas is incomplete; officers in charge of environmental protection are inadequate and unqualified; investment funds for environmental protection do not meet requirements. So far, most of rural areas in the whole country are struggling to implement and meet the environmental criteria 17 in the national set of criteria for new rural areas, the rural communes getting such criteria account for small proportion. Specifically, "by the end of 2015, in the whole country, there are 1,674 communes (accounting for 18.7\%) recognized to get the new rural standards and 11 units at district level recognized to get the new rural standards according to the Decision issued by the Prime 
Minister, in which the percentage of communes implementing the criteria No 17 only accounts for $42.4 \%$, a criteria getting the lowest ratio at this time"[10].

Thus, we can see, although the Party and State of Vietnam always attaches importance to rural ecological environmental protection but environmental pollution, especially in rural areas is very serious. Therefore, in the future, Vietnam should consider the rural ecological environmental protection is an inevitable step in the strategy of sustainable agriculture development and new rural area development in the period of promoting industrialization and modernization of the country.

\section{MAIN SOLUTIONS}

Derived from practical requirements on protection of rural environment towards a sustainable development of the agriculture, every Vietnamese citizen joins hands to implement basic and synchronized solutions.

Firstly, strengthen the propaganda on the mass media and communication activities as well as legal education on rural environment at schools and in the society, in order to raise awareness, responsibility of environmental protection at all levels and sectors and each citizen, especially the younger generation. Develop environmentally friendly cultural behavior based on innovative thinking, methods of implementation, behaviors, sense of responsibility to the nature and the environment. This is defined as the solution appropriate to current socioeconomic conditions of our country in which is very strategic and long term.

Secondly, strengthen the State management of environmental protection in rural ecological environment. Perfect the legal system, mechanisms and policies on environmental protection; clearly define appropriate responsibilities and assignment of tasks of environmental protection, rural waste management across the sectors and levels, overcome duplication in management. Develop inter-sectoral and inter-regional coordination mechanisms; mechanisms so that people effectively monitor natural resources exploitation management, environmental protection and adaptation to climate change. Focus on inspection, supervision and construction of sanctions which are strong enough to deter violators against Environmental Protection Law No. 55/2014 / QH13.

Thirdly, promote socialization in protection of rural ecological environment, create a legal base, mechanisms and policies to encourage individuals, organizations and communities to participate in environmental protection. Form the type of agencies on consultancy, assessment, accreditation and certification of environmental protection; encourage all economic sectors to participate in the services of collecting, transporting, recycling and treating waste and other services for environmental protection. Focus on formulation and implementation of regulations, conventions or commitments on environmental protection and the environmental self-management models of communities in rural areas. Develop mass movement in rural areas, mobilize people to actively participate in environmental protection. Detect and replicate advanced models in the protection of environment in rural areas; attach rural ecological environmental protection to cultural life construction movement of people and national target program on building new rural areas with environmental standards.

Fourthly, pay attention to development planning of industrial parks and clusters, vocational villages in the rural areas, ensure high scientific manner, based on the thorough and comprehensive calculation of development trends to offer appropriate policies, avoid rampant, inconsistent and overlapping planning. For industrial parks in rural areas at the present, need to offer compulsory regulations on the requirements to ensure safety, environmental hygiene; build a system of wastewate collection and treatment before operation license is issued and etc.

Fifthly, promote scientific research, technology application and training of human resources in rural ecological environment. Step up the baseline surveys, monitoring, forecasting and warnings of natural resources and environment in rural areas. Make research, application and transfer of technological solutions for pollution treatment and overcome environmental recession and incidents; make efficient use of natural resources and energy; make application and development of clean and environmentally friendly technologies towards a clean agriculture. Strengthen training of human resources in the environment, offer policies to encourage qualified environmental officers to work in rural areas. Select appropriate technologies in conformity with economic conditions, management skills and practices of rural areas to disseminate applications; enhance recycling and reuse of waste in agriculture.

Sixthly, actively expand international exchange and cooperation in actively responding to climate change and environmental protection. Participate actively in international and regional activities on the environment; make full implementation of international treaties, international commitments, programs and projects on environmental protection in line with national interests. Make close cooperation with its neighbourhood countries and other countries in the region to solve the inter-country environmental problems. Make effective use of financial resources, technology, make proactive approach to new technology from foreign countries and international organizations and individuals in the protection of environment in rural areas. /. 


\section{REFERENCES}

[1]. Dan.Xuan.To.,Vien.Van.Le., Hung.Trong.Do., [2013], the new rural area development in Vietnam: New Vision, New Management Organization, a new step, Agriculture Publishing House, Hanoi.

[2]. Duyet,P, [2011], Adjust and change foreign economic strategy of China's foreign policy in the post financial-currency crisis period, Institute for Strategic Studies Foreign Policy. China Central Party School.

[3]. Environmental Protection Act and its implementing decree [2005], National Political Publishing House, Hanoi.

[4]. Greenpeace,[2014], Annual reports about how-is-greenpeace-structured. [Online] Available: http://www.greenpeace.org/international/en/about/how-is-greenpeace-structured/reports/.

[5]. Hoa, V. Trac., [2000], China- serious challenges of the new century, China Social Science Publisher.

[6]. International conventions on environmental protection [1995], Hanoi, Vietnam: National Political Publisher,

[7]. Marx,H.K., and Engels, F, [2002], Full episode, episode 20, National Political Publisher, Hanoi, Vietnam, Pg 477-644-652-654-720.

[8]. Marx, H.K., [2002], The economic-philosophical draft 1844, Hanoi, Vietnam: Truth Publisher.

[9]. Pham Huy Thong, Pham Thanh Trung, Nguyen Thi Thuong, [2016], philosophy basis of relationship between environmental protection and transformation of economic development method in developing countries, International Journal of Recent Scientific Research, Volume: 7 (4) April - 2016, pg 10643-10647.

[10]. Ryle, H., and Martin M, [1998], Ecology and Socialism, London: Radius.

[11]. Vietnam's Ministry of Agriculture and Rural Development National Conference summary 2010-2015 five-year phase of new rural construction of the national target program implementation [2015].

[12]. UNDP, . [2006], Human Development Report . New York: UNDP.

[13]. UNEP [2011],"Towards a green economy, roadmap for sustainable development and poverty reduction. Summary report serving policy makers. Viet Nam: Agriculture Publisher. 